\title{
Identifying Factors Affecting Students' Academic Achievement in Science and Mathematics in Primary Schools of Hawassa City
}

\author{
Reta Regassa Jetu ${ }^{1 *} \quad$ Henok Wariso ${ }^{2}$ \\ 1.Department of Biology, Hawassa College of Teachers Education, Ethiopia \\ 2.Department of Statistics, Hawassa University, Ethiopia
}

\begin{abstract}
The main objective of this study was to investigate factors affecting students' academic achievement in science and mathematics in primary schools of Hawassa city. A self-developed, structured and semi structured questionnaire was used to obtain information from the students, teachers and head teachers on the variables under study. Descriptive survey research design was adopted for the study. From the total of 10 cluster schools available in Hawassa city administration, 4 cluster schools were selected as our first stage sample. Since, the elementary unit for the study is student from grade 5 to grade 8; the required sample size was taken from total students learning in grade five to eight in the selected clusters schools. The results of the study indicated that low studying habit; low follow up the progress of students by their parents, low education level of parents and low monthly income status of parents are the major challenging factor for successful academic achievement of students in science and mathematics.
\end{abstract}

Keywords: Academic achievement, Primary education, Motivation, Academic environment, Science education DOI: $10.7176 / \mathrm{JEP} / 10-10-06$

Publication date: April $30^{\text {th }} 2019$

\section{Introduction}

\subsection{Background of the study}

Science and technology play an important role in the modern world. Science education is believed to serve as the foundation of technological development and a key factor in economic growth. Science and mathematics subjects are identified as being 'critical' to the future supply of

qualified scientific workforce and are of strategic importance to the nation because of the increased competition from rapidly advancing economies around the world (HMSO, 2004).

Discussing factors affecting students' academic performance will require us to look the concept of poor performance. According to Aremu (2000), poor performance is a performance that adjudged by the examinees/testees and some significant as falling below an expected standard. The interpretation of this expected or desire standard is better appreciated from the perpetual cognitive ability of the evaluator of the performance. The evaluator or assessor can therefore give different interpretations depending on some factors. While, Bakare (1994, as cited in Abdullahi, 2013) described poor academic performance as any performance that falls below a desired standard.

A growing body of research provides additional factors which could have an impact on students' achievement such as gender, family structure, parents' educational level, socio-economic status, parent and student attitudes toward school, and parent involvement (Campbell et al. 2000; Epstein, 1991; Fennema and Sherman, 1976, 1986; Fluty, 1997).

The education policy and education sector development program of Ethiopia emphasizes on the importance of science and technology so as to secure the growth and development in the country. Achieving the vision of transforming Ethiopia into a middle-income country by 2025 demands for transformation of the economy through application of science and technology as instruments to create wealth. In line with the key priorities of the current growth and transformation plan, a large demand is expected capable citizens who can contribute to make the country competitive in the increasingly knowledge-based global economy. It has become mandatory for the education system to manifest overall improvement in sciences, mathematics, engineering and technology. This calls for a continued expansion and equitable access to high-quality general education with promising foundations in science and mathematics and special efforts to improve the science literacy level of the population.

\subsection{Statement of the problem}

According to the New Education and Training policy of Ethiopia primary education has two cycles. The first cycle 1-4 and the second cycle 5-8. The policy also gives emphasis to the expansion of education in general and primary education in particular (TGE, 1994).

In the last two decades Ethiopia has made significant progress in education. To mention a few: Access to all levels of the education system has increased in a rapid rate; the number of schools and institutions has grown considerably; qualification of teachers, availability of equipment and other inputs is also by far better than before; the participation of girls has grown-up in substantial index; contents and organization of education were made 
more relevant to the diversified population of the country.

Despite all these actions students' achievement has not yet sufficiently improved. Particularly, as various studies have proved (Ethiopian Third National Learning Assessment of Grade Eight Students, 2008) the attainment of students in science and mathematics is blow the standard. On the other end the country has a vision of transforming into a middle income country in 2025. But, without the improvement of the quality of science and mathematics education development is unlikely. In spite of the desire for technological development, couple with the fact that science is a very vital subject for technological development and as such, its teaching and learning as well as students' poor academic performance have become a source of concerns to all stakeholders. It is, therefore, very critical to mend the situation of these subjects at all levels of the education system.

Academic performance, which is measured by the examination results, is one of the major goals of a school. Hoyle (1986) argued that schools are established with the aim of imparting knowledge and skills to those who go through them and behind all this is the idea of enhancing good academic performance. There is lack of sufficient research in the case of Hawassa city as to what factors affect students' academic performance in science and mathematics. This study aims to investigate factors affecting academic performance of primary school students in science and mathematics in Hawassa city.

\subsection{Research Questions}

The study focused to answer the following research questions

i. What is the level of academic performance of students in science \& mathematics in primary schools in Hawassa city administration?

ii. Is there difference in academic achievement between male and female students?

iii. What are the most influential factors that affect students' academic achievement in science \& mathematics in primary school?

\subsection{General objective}

The objective of the study is to investigate factors affecting academic achievement of students' in science \& mathematics in primary schools of Hawassa city.

\subsubsection{Specific objectives}

- To determine the school based factors that affect student performance in science \& mathematics in primary schools

- To identify the student related factors that affect student performance in science \& mathematics in primary schools

- To investigate the parents related factors that affect student performance in science \& mathematics in primary schools

- To assess demographic and socio-econmic factors that affect student performance in science \& mathematics in primary schools

- To evaluate whether there is significant difference in academic achievement between male and female students?

\section{Methodology}

\subsection{Study Area \& Population}

The study was conducted in Hawassa city Administration which is the capital city of southern nation's nationalities \& people's regional state (SNNPRS). schools.

The target groups for the study are students from grade 5 to 8 in 2018 in the city governmental primary

\subsection{Method of Data Collection}

\subsubsection{Data collection instruments}

Students' attitude towards science and mathematics was measured using Likert scale. A self-developed, structured and semi structured questionnaire was used to obtain information from the students, teachers and head teachers on the variables under study. Using questionnaires, checklists, and achievement score, the study was collected information on achievement test scores, teaching methods, student textbook ratios, student gender, class size, and other auxiliary factors. The results of the students' average point was collected and analyzed with mean and standard deviation.

Focus group discussion was conducted with students and teachers to collect information regarding factors that are expected to affect the performance of students. In depth interview was employed to school principals, supervisors and parent- teachers association (PTA) to collect qualitative data on various factors that may affect the academic achievements of students. Document analysis was used to assess students profile strictness, attendance, previous academic achievements. 


\subsection{Sampling Design and Techniques}

Descriptive survey research design was adopted for the study. Sampling methods are scientific procedures of selecting those sampling units which would provide the required estimator with associated margins of uncertainty arising from examining only a part of the population. From the total of 10 cluster schools available in Hawassa city administration, 4 cluster schools were selected as our first stage sample. Since, the elementary unit for the study is student from grade 5 to grade 8; the required sample size was taken from total students learning in grade five to eight in the selected clusters schools.

\subsection{Sample Size Determination}

In planning sample survey, one of the basic considerations is sample size determination. Factors, which decide the scale of the survey operations, have to do with cost, time, operational constraints and desired precession of the results. Since it is desirable to have high levels of precision, it is also desirable to have larger sample sizes as the larger the sample the more precise estimates would be. But cost, time and operational constraints limits the decision. Assessing these constraint and statistically tolerable error for desired levels of the precision from preliminary study, the sample size for the study was determined using formula as:

$$
\boldsymbol{n}=\frac{N Z^{2} \frac{\alpha}{2} S^{2}}{N d^{2}+Z^{2} \frac{\alpha}{2} S^{2}}
$$

$\mathrm{N}$ : Total number of population

Where

$$
d=\varepsilon \bar{y}: \text { Absolute error }
$$

$S^{2}$ : Variance from pilot or preliminary survey

$Z_{\alpha / 2}$ : Value of standard normal deviate at level of significance, 1.96 at $95 \% \mathrm{CI}$,

$$
\alpha=0.05 \text {. }
$$

\subsection{Study Variables}

In this study, we had dependent and explanatory variables. Dependent (response) variable: Academic achievements of students. Independent (explanatory) variables: the independent variables of the study are categorized as demographic and socio-economic factors, student factors and school factors as follows. Demographic and socio-economic factors: (sex, age, family size, education level of family, parents occupation, economic status of family, Parents involvements). School factors (teachers qualification, teachers experience, text book availability, laboratories availability, extra-co-curricular activities, teacher student interaction, principal leadership and peer relation). Student factors: (attitudes of student towards the mathematics and natural science, aspirations, class attendance).

\subsection{Data Analysis}

Data was analyzed based on information obtained from the completed questionnaire, focus group discussions (FGDs), Parent Teacher Associations (PTAs) and some documents of students (portfolio). In analyzing the data both descriptive and inferential statistical analysis method was used. The statistical package for social science (SPSS) was used for quantitative data analysis to determine frequency, percentages, mean, standard deviation and other inferential results. However; some qualitative data obtained through FGD and PTA instruments was analyzed manually. Descriptive statistics such as frequency distributions, diagrams, pie-charts and graphs were employed to describe the general characteristics of the data. Frequency values were used to show students' distribution in terms of grade levels and gender, and the gathered data were analyzed by using independentsamples t-test and one way ANOVA in the SPSS program. The Pearson product-moment correlation coefficient (r) was used to compute the relationship between average points, parents' social economic status, school background and academic performance.

\section{Result}

This chapter includes presentation and analysis of the data, and interpretation of the results. The primary data used in the analysis of the study were collected from students from grade 5-8, parents of students, principals, supervisors and PTAs by using different data collection instruments (questionnaires, interviews, FGDs and PTAs). Other data on the score of students out of 100 at the end of the semester, student profile strictness, dropout and attendance were collected from secondary source. From four selected clusters, 302 students were selected by using simple random sampling and given questionnaires; six questionnaires were omitted due to none response rate and three questionnaires were rejected due to error in response. Finally, 293 students filled questionnaires and used for quantitative analysis. The validity of questionnaire was analyzed to test reliability of 
results. Accordingly, the croachbanch alpha was found to be 0.87 which shows that the instruments were valid. In order to assure whether the variables are in their right component or not the study used principal component analysis. Therefore, the study analyzed the data gathered by these different sources and instruments and the decisive results were found accordingly.

4.1 Descriptive characteristics of some socio-economic factors

Table 1. Socio-economic factors of respondents (for non-continuous)

\begin{tabular}{|c|c|c|c|c|c|}
\hline S.n & Factors & Possible values & Frequency & Percent & $\begin{array}{l}\text { Cumulative } \\
\text { frequency }\end{array}$ \\
\hline \multirow[t]{4}{*}{1} & \multirow[t]{2}{*}{ Sex of respondents } & Female & 146 & 49.8 & 49.8 \\
\hline & & Male & 147 & 50.2 & 100 \\
\hline & \multirow{5}{*}{$\begin{array}{l}\text { Monthly income of respondent } \\
\text { family }\end{array}$} & $<1000$ & 11 & 3.8 & 3.8 \\
\hline & & $1000-2000$ & 84 & 28.7 & 32.4 \\
\hline \multirow[t]{3}{*}{2} & & $2000-3000$ & 97 & 33.1 & 65.5 \\
\hline & & $3000-4000$ & 69 & 23.5 & 89.1 \\
\hline & & $>4000$ & 32 & 10.9 & 100.0 \\
\hline \multirow[t]{5}{*}{3} & \multirow{5}{*}{$\begin{array}{l}\text { Education level of fathers of } \\
\text { respondents }\end{array}$} & Illiterate & 2 & 0.7 & 0.7 \\
\hline & & $1-8$ & 19 & 6.5 & 7.2 \\
\hline & & $9-12$ & 71 & 25.3 & 32.4 \\
\hline & & Certificate & 97 & 33.1 & 65.6 \\
\hline & & $\begin{array}{c}\text { Diploma and } \\
\text { above }\end{array}$ & 101 & 34.5 & 100.0 \\
\hline \multirow[t]{5}{*}{4} & \multirow{5}{*}{$\begin{array}{l}\text { Education level of mothers of } \\
\text { respondents }\end{array}$} & Illiterate & 6 & 2.0 & 2.0 \\
\hline & & $1-8$ & 30 & 10.2 & 12.3 \\
\hline & & $9-12$ & 82 & 28.0 & 40.3 \\
\hline & & Certificate & 87 & 29.7 & 70.0 \\
\hline & & $\begin{array}{c}\text { Diploma and } \\
\text { above }\end{array}$ & 88 & 30.0 & 100.0 \\
\hline
\end{tabular}

From the total of 293 respondents included in the analysis of the study, 146(49.8\%) of students are female and $147(50.1 \%)$ of students are male. This means that almost the number of male and female students included in the selection and analysis was almost proportional. As far as the monthly income of students family is concerned in categories, 11(3.8\%) get a monthly income below 1000, 84(28.7\%) get a monthly income between 1000 and 2000, 97 (33.1\%) get a monthly income between 2000 and 3000, 69(23.5\%) get a monthly income between 3000 and 4000 and the rest 32(10.9\%) get a monthly income above 4000 . The result from the cumulative percentage frequency from the same table shows that about $192(65.5) \%$ of student families gets monthly income below 3000. This shows that most families get income below 3000 .

Considering the education level of their fathers, $6(2.0 \%)$ are illiterate, $30(6.8 \%)$ are from grade $1-8,71$ (25.3) are 9-12, 97(33.4\%) are certificate and 101 (34.5\%) are diploma and above. Regarding the education level of their mothers, $2(0.7 \%)$ are illiterate, $19(10.2 \%)$ are from grade $1-8,82(28.0)$ are $9-12,87(29.7 \%)$ are certificate and $88(30 \%)$ are diploma and above. This indicates that the education levels of students' parents are at low level.

Table.2 Descriptive characteristics of age of students and their families.

\begin{tabular}{lcccc}
\hline Age factors & $\mathrm{N}$ & \multicolumn{2}{c}{ Mean } & Std. Deviation \\
& Statistic & Statistic & Std. Error & .109 \\
\hline Age of respondents & 293 & 14.23 & .738 & 1.867 \\
Age of father of respondents & 293 & 48.55 & .582 & 12.634 \\
Age of mother of respondents & 293 & 39.41 & 9.970 \\
\hline
\end{tabular}

As it can be seen from table 2 above, the average age of students is 14.23 with standard deviation of 1.87.The standard deviation is small showing that the age of majority of students is concentrated around average value (14.23). The average age of their fathers and mothers are 48.55 and 39.41 with standard deviation of 12.63 and 9.97 respectively.

4.1.1 Result on academic achievement of students

Table 3.The descriptive nature of academic achievements of students in mathematics and natural science.

\begin{tabular}{lccccc}
\hline Score of students & N & Minimum & Maximum & Mean & Std. Deviation \\
\hline Score of student in Science & 293 & 33 & 93 & 59.79 & 12.50 \\
Score of student in mathematics & 293 & 23 & 100 & 57.73 & 13.99 \\
Score of Students & 293 & 27 & 97 & 58.79 & 11.54 \\
\hline
\end{tabular}

Table 3 above shows the back ground information of academic achievement of students in the study. It is 
possible to see from this table that the average score of students in natural science is 59.79 .79 with standard deviation of 12.50 while that of mathematics is 57.73 with standard deviation of 13.99 . The larger value of standard deviation in score of mathematics shows that there is higher variation in the score of students in mathematics than natural science. This result is also supported by the range values i.e. the score of students in mathematics ranges from 10 to 100 while that of natural science ranges from 33 to 97 .

\subsection{Descriptive Quantitative Analysis Results}

4.2.1 Student related Factors

\subsubsection{Attitudes of students towards science and maths}

Attitudes of an individual can be considered as a good or bad opinion towards an event, reaching a decision and reflecting it on his behaviors. Attitudes are related to mathematics and natural science through developing the need, interest and confidence of students in science and mathematics lessons.

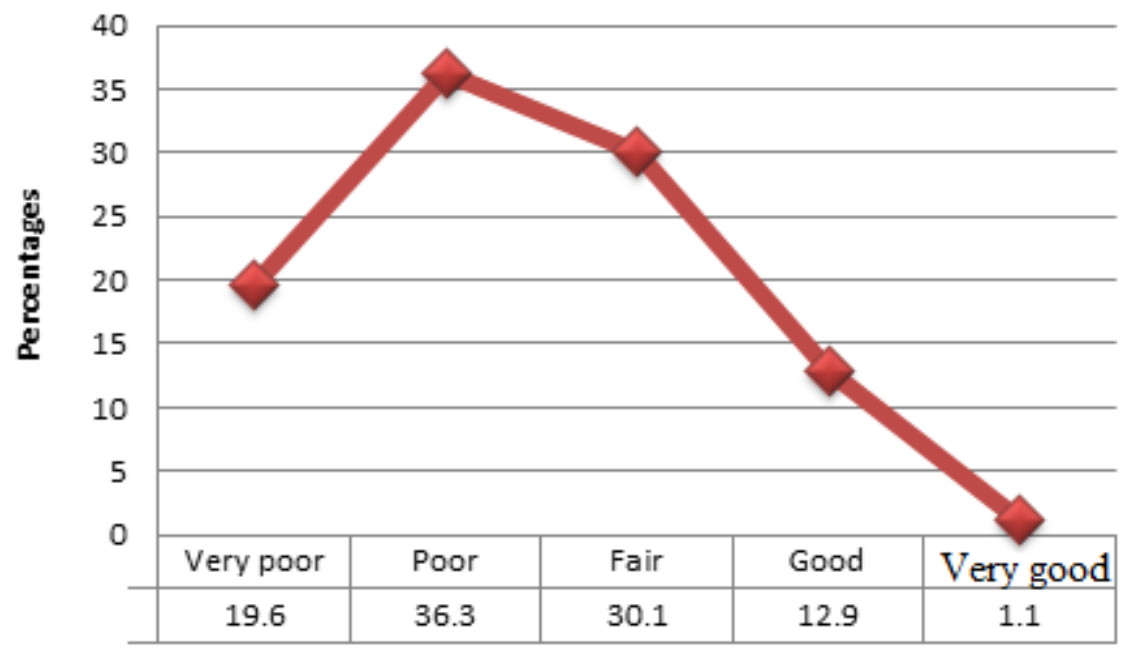

Figure 1. Attitudes of students towards science and maths

As depicted in the figure1, majority of response $(55.90 \%)$ of students respond that their confidence (attitudes towards mathematics and natural science is negative (very poor and poor) i.e they have no confidence that they can score good performance in science and maths. This means that negative attitudes towards science and maths can be taken as one of the major factor that leads students to low achievement in science and maths.

\subsubsection{Studying Habit of Students}

It is clear that studying is one major determinant for the success of student performance. In addition practicing and rehearsing lesson daily is an important habit of for better academic achievement of students in any lesson in general and in science and maths in particular. 


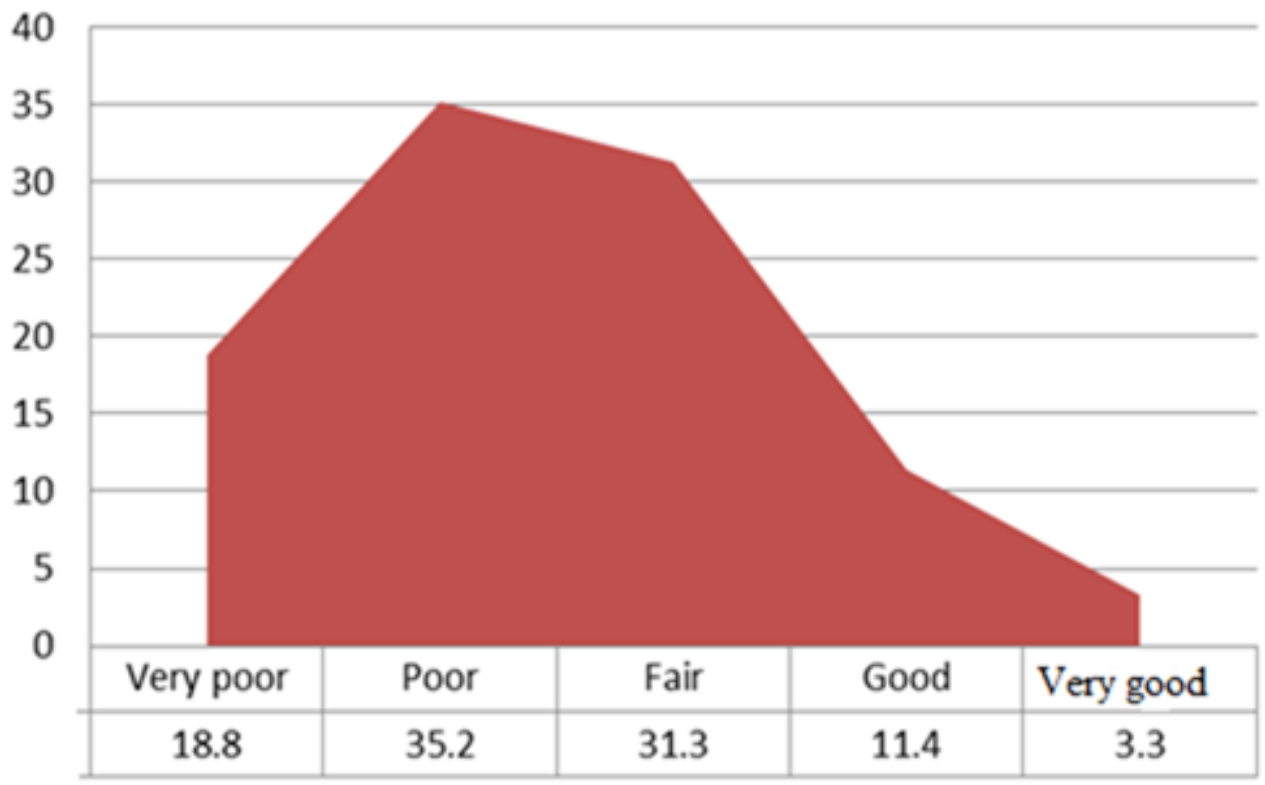

Figure.2 Studying habits of students

Considering the studying habit of students, $18.8 \%$ of respondents reported that their studying habit is at very poor level, $35.2 \%$ of respondents responded that their studying habit is at poor level, $31.3 \%$ of student reported that their studying habit is at medium level, $11.4 \%$ of respondents responded that their studying habit is at high level and $1.7 \%$ responded that they are at very high level. The negative (very poor and poor) response of students accounts $54.0 \%$. This result also indicated that the low studying habit of respondents is one major challenging factor for academic achievement of students.

\subsubsection{Family Related Factors}

Family related factors (following up the progress of students, motivating their students to learn, education level of the parents, provision of necessary educational material and income status of the parents) are some of expected contributors to academic achievement whose effect is going to be studied in this study. Parents provide school supplies, supervision of activities, and home environments that are learner friendly, participate in committees, parent-teacher organizations, and other groups involved in decision making for the school.

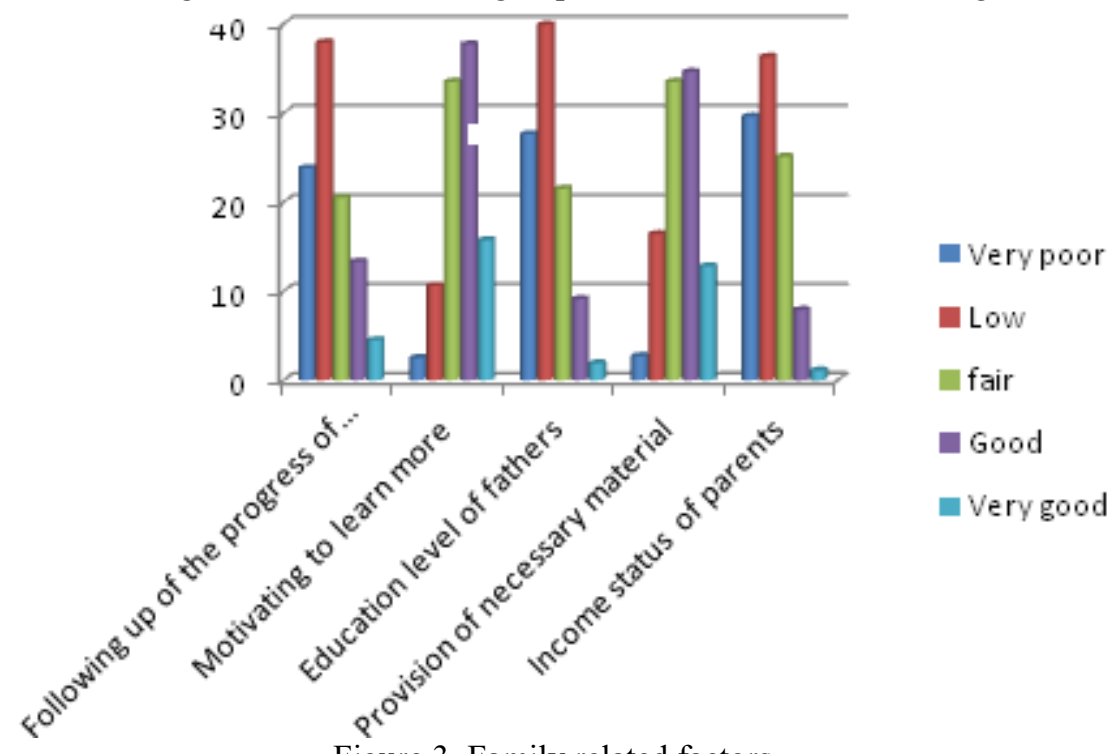

Figure 3. Family related factors

The result from above figure 3 can be interpreted in two ways; i.e the left bars of three factors (following up the progress of students by their parents, education level of parents and monthly income status of parents) in above multiple bar diagram are highly frequent indicating that the responses of students are concentrated at very low and low level. This asserts that the three factors are the major problem area for the successful academic achievement. Whereas the right bars for the two factors (motivating students to learn and provision of necessary 
materials for the students) in the same multiple bar diagram are highly frequent showing that responses are concentrated at medium and above levels of the factors. This is an indication of being moderate problem and not considerable challenge for the academic achievement of the students.

\subsubsection{Teachers Related Factors}

Table 4. Descriptive quantitative analysis result on teacher related factors

\begin{tabular}{lccccc}
\hline Teacher related factors & Very low & Low & Medium & High & Very high \\
\hline Qualification of teachers & $8(2.73 \%)$ & $36(12.28 \%)$ & $108(36.86 \%)$ & $115(39.25 \%)$ & $26(8.87 \%)$ \\
Commitment of teachers & $32(10.92 \%)$ & $121(41.296 \%)$ & $97(33.11 \%)$ & $40(13.65 \%)$ & $3(1.03 \%)$ \\
Experience of teachers & $5(1.71 \%)$ & $31(10.58 \%)$ & $95(32.42 \%)$ & $111(37.88 \%)$ & $53(18.09 \%)$ \\
Assessment method of teachers & $21(7.17 \%)$ & $92(31.39 \%)$ & $107(36.52 \%)$ & $68(23.21 \%)$ & $5(1.71 \%)$ \\
Teaching method of teachers & $7(2.39 \%)$ & $69(23.55 \%)$ & $123(41.98 \%)$ & $79(26.97 \%)$ & $15(25.12 \%)$ \\
Teachers approaches to students & $2(0.68 \%)$ & $31(10.58 \%)$ & $90(30.72 \%)$ & $116(39.59 \%)$ & $54(18.43 \%)$ \\
Workload of teachers & $4(1.37 \%)$ & $10(3.41 \%)$ & $109(37.20 \%)$ & $137(46.76 \%)$ & $33(11.26 \%)$ \\
\hline
\end{tabular}

Results from table 4 above can be described in three ways. The first interpretation refers to qualification of teachers, experience of teaching, approaches of teachers to their students and weekly workload of teachers. For these factors majority of respondents (above 85\%) replied that the medium, high and very high level nature of the factors. This shows that there is no considerable problem with respect to these factors for better academic achievement of students in science and maths.

Regarding the two factors (assessment and method of teaching used by the teachers), most responses are concentrated at medium level and some responses are dispersed to lower and higher extremes. From this it is possible to deduce that there is considerable problem, but not serious with respect to these factors which influenced the academic success of students in science and maths. However, considering the commitment of teachers, result from the same table indicated that above $50 \%$ or respondents replied that the commitment of teachers is at low level. This result shows that commitment of teachers is the most serious problem for the better academic achievement of students.

\subsubsection{School related Factors}

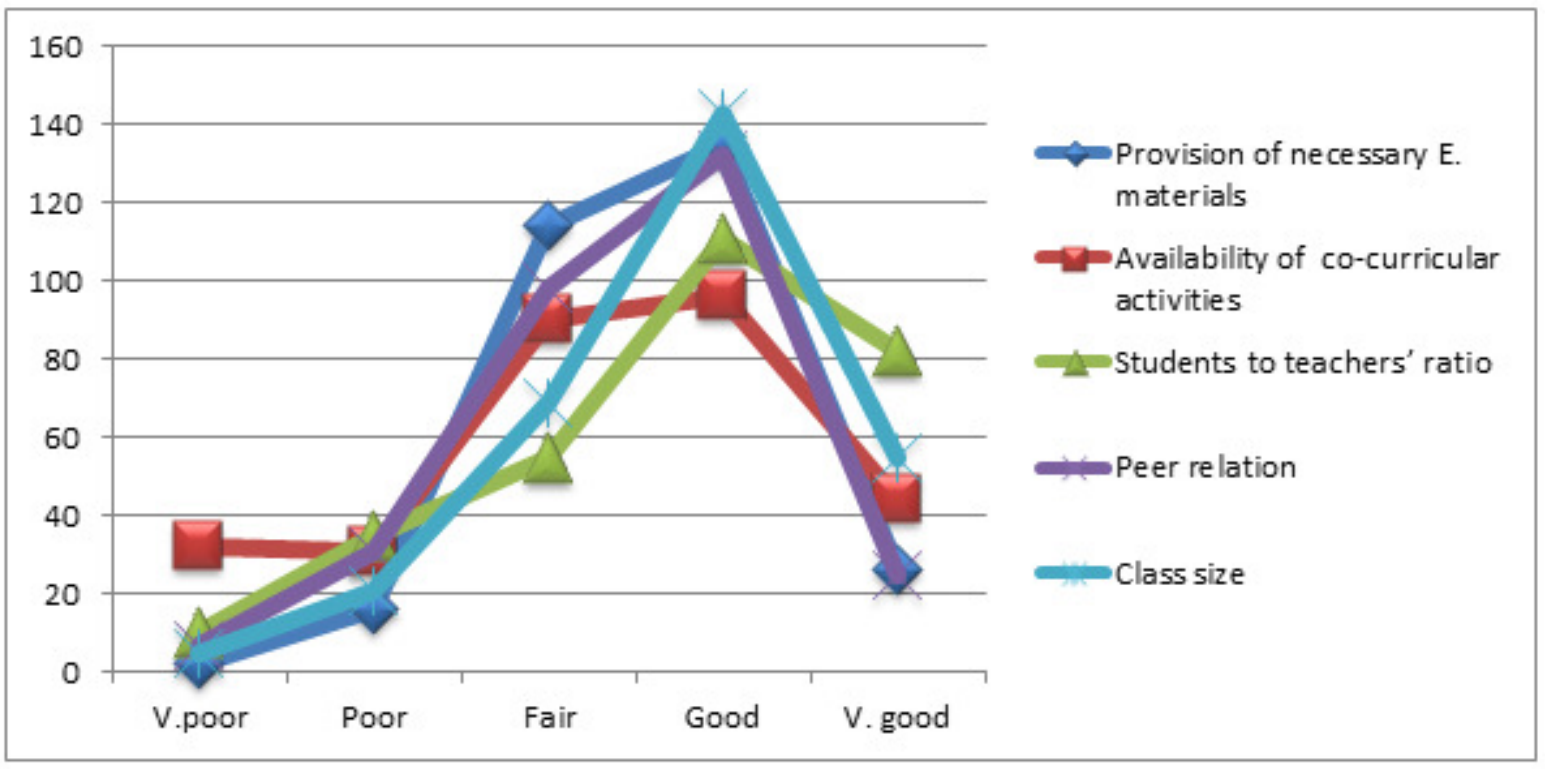

Figure 4. School related factors

The above figure shows, the distribution of values for all factors (provision of the necessary materials, availability of co-curricular activities, students to teacher's ratio, peer relation and class size) are around medium and above it. From these we can say, although there are moderate problems in school factors, they are not the serious ones for better academic achievement of students in science and maths in the study area.

\subsection{Results of regression coefficients}

The study used multiple liner regression analysis to investigate the relationship between response (score of students in mathematics and natural science) and each of explanatory variables student related factors, teachers related factors and school related factors where each predictor is represented by many indicators. The values of estimated regression coefficients obtained by least estimation procedure are displayed in table 5. 
Table 5. The relative effect of explanatory variables

\begin{tabular}{lcccc}
\hline Related factors Component Scores & \multicolumn{2}{c}{ Explanatory } & Regression Coefficients & Sig. \\
& Factors & $\mathrm{B}$ & Std. Error & \\
\cline { 2 - 5 } Student Related Factors & Constant & 17.84 & 2.608 & 0.000 \\
& studying habit of students & 1.71 & 0.89 & .001 \\
Family Related Factors & Attitudes towards MNS & 3.01 & 1.57 & .000 \\
& Following up students progress & 2.23 & .97 & .000 \\
Teachers Related Factors & Education level of father & 1.73 & 1.02 & .009 \\
& Monthly income of families & 2.65 & 1.217 & .000 \\
& Commitment of teachers & 2.22 & 0.98 & 0.000 \\
& Teaching method used & 1.54 & 1.43 & 0.009 \\
& Assessment method used & 1.29 & .42 & .007 \\
\hline
\end{tabular}

Student related factors (attitude of students towards science and maths, studying habit of students), Family related factors (follow up of students progress by their parents, motivation given to students to learn by their parents, education level of parents, provision of the necessary materials for learning and income status of students parents), Teachers related factors (qualification of teachers, commitment of teachers, experience of teachers, assessment method used by the teachers, teaching method used by the teachers, teachers approaches to their students and weekly workload of teachers) and School related factors (provision of education material, availability of co-curricular materials, teacher to student ratio, peer relation and class size) on response variable (Academic achievements of students in science and maths). The Intercept $\beta_{0}=17.84$ is the academic achievement of students (score) when all explanatory variables assume the value zero. This value represents that student can score 17.84 out of 100 without any input of predictors included in the model (student related factors, family related factors, teachers related factors and family related factors).

All signs of values of regression coefficients in this table are positive indicating that all explanatory factors (student related factors, family related factors and teachers related factors are positively related with academic achievements of students in science and maths. However, the relative effect of explanatory variable is proportional to the magnitude of corresponding regression coefficients. This means that the factor corresponding with larger regression coefficient plays larger role and vice versa in determining the academic achievements of students in science and maths.

For instance, the coefficients of attitudes of students towards science and maths i.e. $\boldsymbol{\beta}_{2}=\mathbf{3 . 0 1}$ is the largest value of all explanatory factors included in the model indicating that the most determinant factor for less academic achievement of students in science and maths is negative attitudes of students while the minimum value from significant factors is the coefficient of assessment method used by the teachers i.e. $\beta_{8}=1.29$ showing that it played the least role for low academic achievement of students.

Considering to the significances of coefficients, all regression coefficients displayed in table 5 corresponding are statistically significant since their respective p-values are less than the level of significance i.e. $\alpha=0.05$. This means that according to result of the study, Student related factors (with significant indicators of attitudes of students towards science and maths and studying habit of student), Family related factors (with significant indicators of follow up of students progress by their parents, motivating their students to learn, education level of their parents, provision of the necessary materials for learning and income status of their parents) and Teachers related factors (with significant indicators of commitment of teachers, assessment method used by the teachers, teaching method used by the teachers) were found to be significant factors to affect the academic achievement of students in the study area. Whereas, the p-values of other factors which were included in the model whose significance was to be tested were not found to be statistically significant and not displayed in this table. In addition, for all indicators of school factors we would not get statistically sufficient evidence to say that they were responsible for poor performance of students in science and maths. However, from the analysis of quantitative (descriptive statistical analysis) and qualitative analysis (Interviews from principals, supervisors and FGDs) show that there is some gaps that has to be filled in order to improve the academic achievement of students.

\subsubsection{Interpretations of regression coefficients}

The value $\beta_{1}=1.71$ (coefficient of studying habit $f$ student) indicates that when studying time of students change by one unit, score of students is changed by 1.71 units keeping other factors effect to be constant. This means that when the time of studying of students increases by one unit the students score is increased by 1.71 units with the same direction. The value $\beta_{2}=3.01$ (coefficient of attitude of students towards science and maths) means that when commitment of teachers change by one unit, score of students changed by 3.01 units keeping other factors effect to be constant. The sign of coefficient $\left(\beta_{2}=0.301\right)$ positive indicating that any change made on commitment of teachers will change the academic achievements of students in the same direction. The coefficients of all explanatory factors included in the model are interpreted in the same way. The value $\beta_{3}=2.23$ (coefficient of parents follow up of their students' progress) indicates that when the follow up of the parents 
change by one unit, score of students is changed by 2.23 units keeping other factors effect to be constant. This means the increase or decrease of follow up of parents will increase or decrease the academic achievement of students in science and maths by the magnitude 2.3 and with the same direction. The value $\beta_{4}=2.65$ (coefficient of income status of parents) indicates one unit change in that when studying time of students change by one unit, score of students is changed by in income status of parents will change academic achievement of students in science and maths by the magnitude 2.65 and with the same direction. Besides the education level of parents is interpreted in the same way. The value $\beta_{6}=2.22$ (coefficient of commitment of teachers) asserts that one unit change in commitment of teachers will change the score of students in science and maths by the magnitude 2.22 and with the same direction. Other coefficients of teacher related factors are interpreted in the same way.

Finally, using the estimated regression coefficients, we can model the academic achievement of the students in Hawassa City by:

$\mathrm{AA}=17.84+1.71 \mathrm{sh}+3.01 \mathrm{As}+2.23 \mathrm{~F}+1.73 \mathrm{E}+2.65 \mathrm{I}+2.22 \mathrm{C}+1.54 \mathrm{~A}+1.29 \mathrm{M}$

\subsubsection{Comparison of academic achievement between male and females}

One of the aims for the study is to compare the academic achievement between male and female students. To achieve the objective the study, we used both descriptive and inferential statistics using equivalent independent sample t-test (Mann-Witnney test) for ordinal data.

Table 6. Descriptive result on comparison of academic achievement between male and female student

\begin{tabular}{lccccc}
\hline Score categories & Sex of Students & $\mathrm{N}$ & Mean & St.Deviation & St.Error \\
\hline Score of students in Science & female & 146 & 57.92 & 11.666 & .966 \\
& male & 147 & 61.65 & 13.059 & 1.077 \\
Score of students in mathematics & female & 146 & 56.36 & 13.335 & 1.104 \\
& male & 147 & 59.10 & 14.528 & 1.198 \\
Score of students & female & 146 & 57.4486 & 11.22032 & .92860 \\
& male & 147 & 60.1224 & 11.73707 & .96806 \\
\hline
\end{tabular}

From table 6 above, it can be seen that the mean value of score of female and male students in science are 57.92 and 61.55 while in mathematics the respective values are 56.36 and 59.10. In both case the mean score of male student is better than the average score of female students.

\section{Discussion}

The study focus on identifying factors that affect the academic achievement of students in science and mathematics in primary school of Hawassa city in 2017 - 2018. Low studying habit of respondents is one major challenging factor for academic achievement of students. The result of the study consistently showed that negative attitudes towards science and mathematics in primary school students can be taken as one of the major factor that leads students to low achievement. Attitude is described as an individual's tendency to behave positively or negatively towards any event, object or group of people (Turhan etal., 2008). Attitudes are related to academic achievement of students in developing the learning environment in time. One of the student features that have an important effect on the learning process for successful academic achievement is student's attitudes towards the lesson (Altınok, 2004; Magno, 2003).

Our study indicated that the majority of students' families get low monthly income. This influences the low achievement of students in science and mathematics. This is similar with other study like Agus and Makhbal (2002) which indicate that students from families of higher income levels perform better in their academic assessment as compared to those who come from families of lower income bracket and Checchi (2000) also concluded that family income provides an incentive for better student performance and richer parents internalize this effect by investing more resources in the education of their children; and that once the investment is undertaken, the students full fill parents' expectation by performing better in their studies.

Socio-economic status is determined to be a predictor of science and mathematics achievement. Studies repeatedly discovered that the parents' annual level of income is correlated with students' science and mathematics achievement scores (Eamon, 2005; Jeynes, 2002; Hochschild, 2003; McNeal, 2001). Socioeconomic status was found significant in primary math and science achievement scores (Ma and Klinger, 2000). Another study found poor academic achievement of Canadian students to be attributable to their low socioeconomic status (Hull, 1990). Socio-economic status was examined and found to be one of the four most important predictors of discrepancy in academic achievement of Canadian students (aged 15) in reading, mathematics, and science by the Program for International Student Assessment (Human Resources Development Canada, Statistics Canada, and Council of Ministers of Education Canada, 2001).

The present study showed that there is low following up of students' progress by their parents.

Parents feel a sense of ownership at school when they know they were involved in creating a policy, providing an activity for students, or changing a policy. Teaching materials and related material inputs that are linked directly to teaching are related consistently to higher student achievement (Feiman-Nemser, 2001; Finn and Achilles, 1999). 
Successful and active involvement of parents is one of the major factors for better academic achievement of students through provision of basic needs, the necessary education materials and creating linkage between school and parents (Epstein and Voorhis, 2001). Besides to this following up of students progress is the major role of parents to sustain the incremental progress of student in academic achievement of their students.

A number of studies indicated that student achievement is correlated highly with the educational attainment of parents (Coleman, 1966). For instance, students whose parents had less than high school education obtained lower grades in mathematics than those whose parents had higher levels of education (Campbell et al., 2000). Research has shown that parents' educational level not only impact student attitudes toward learning but also impact their math achievement scores.

On parents' educational level, Ermisch and Franceconi (2001) say that there is a significant gradient between each parent's educational level and their child's educational attainment.

\section{Concussions and Recommendations 6.1 Conclusions}

The results from student related factors made us to conclude that negative attitudes of students towards mathematics and natural science and low studying habit of student were the significant factors to affect the academic achievement of students. This means that there are negative attitudes of students towards mathematics and science. This may lead to less participation, less confidence or interest in any teaching learning activity of maths and science. Hence, it is clear that the consequences of such student are poor performance in maths and science. The study also concluded that other basic student related factors is poor studying habit of student. However, the attitudes towards mathematics and science and studying habit of student is highly correlated indicating that improving the attitudes of students towards the lesson is one way of increasing the time allotted for study.

As the study indicated parent related factors that influence mathematics and natural science is low education level of parents, low follow up of students by their parents and low income status of their parents. So, we concluded that parents with low education could not guide and encourage their children. This could be due to parents cannot play their role in provision of the necessary educational materials and developing positive attitudes towards mathematics and natural science. Of course there are many ways by which parent education level influences the academic achievement of students. For instance, more educated parents are expected to play their role better in motivating their students in education, participate in any school issues and follow up their students' progress day to day. In addition to this, low monthly income the parents in another parent's related factor that affected the academic achievement of student in maths and science. The result of qualitative analysis from FGDs and Interviews also strongly showed that low level of income is the major factor of low academic achievement of students in all subjects and natural science in particular.

As far as teacher related factors are concerned, commitment of teachers, method of teaching used by the teachers and assessment methods used by the teachers were found to be significant. So, we concluded that in order to bring incremental change on students' academic achievement, more has to be done on these factors of teachers.

\subsection{Recommendations}

Based on the findings of the study, the following recommendations were suggested for improving the academic achievement of student.

From the result of multiple linear regression students related factors that were found to be significant determinant of academic achievement of student were negative attitudes of students towards mathematics and natural science, and low studying habit by the students. Therefore in order to improve the academic performance of student the habit of studying should be improved through motivating them to study by the parents and teachers and other concerned bodies. The negative attitudes of students towards mathematics and natural science should be changed by making students understanding especially by teachers of mathematics and natural science. In addition to these parents should be awarded that it is they themselves who can change the negative attitude of their students towards maths and science. Hence, more has to be done on parents to make them understand that they should follow up the daily progress of their children in order to guide them in a right track.

$>$ From the result of the same model, parents related factors that were responsible for less performance of students were low education level of parents, low follow up of the progress of students by their parents and low monthly income of parents. So, it is important to make parents learn through awareness creation that importance of their involvement in improving the academic achievement of their student. In addition, government and other concerned bodies should work on improving the livelihoods of parents and their education level so as to improve the academic achievement of students.

$>$ From the results of teachers related factors, low commitment of teachers to help students in mathematics and natural science, method of teaching used by the teachers and method of assessment used by the teachers 
were the significant determinant factors of academic achievement of students. It should be clearly understood that it is committed teacher who can play his role in any of the activities taken to improve academic achievement of students. So, in order to make any improvement in academic achievement of students, government and any concerned bodies should work on increasing commitment of teachers through giving training of their profession such as method of assessment and active method of teaching. In addition, incentives provision mechanisms should be developed in such a way that those teachers who did better in playing their role would be awarded. Teachers have to use an active learning method which makes students to participate in teaching learning activities and practically. Above all teachers should be awarded that more work is up to them in improving the academic achievement of students and have to value their profession more than the salary of the payment made to them.

\section{Acknowledgement}

The Authors are highly acknowledged the help and full participation given by all the respondents to the questionnaires and those who fully participate in focus group discussions, without them none of this work would have been possible.

\section{References}

Abdullahi, O. E. (2013). Interrelationship between personal factor and academic achievement in mathematics of Ebira secondary schools students in Kogi state. Ife PsychologlA-An International Journal, 5(1), 154-155.

Agus, A and Makhbul, Z.K. (2002). An empirical study on academic achievement of business students inpursuing higher education: An emphasis on the influence of family backgrounds, Paper presented at International Conference on the Challenges of Learning and Teaching in a Brave New World: Issues and Opportunities in Borderless Education, Hatyai Thailand.

Altınok, H. (2004). Teacher candidates' evaluations of their teaching competencies. Hacettepe University Journal of Education 26, 1-8.

Aremu, E. (2000). Poor academic performance of students in secondary schools. Retrieved June 10, 2013, from http://www.google.com.ng/search?

Bauch, J. P. (1994). Categories of parent involvement. The School Community Journal, 4(1), 53-61.

Campbell, J. R., Hombo, C. M., \& Mazzeo, J. (2000). NAEP 1999 trends in academic progress:Three decades of student performance. Washington, DC: National Center for Education Statistics.

Checchi, D. (2000). University education in Italy, International Journal of Manpower, Vol 21 No 3/4, pp.177-205.

Coleman, J. S. (1966). Equality of educational opportunity. Washington, DC: U.S. Government Printing Office.

Eamon, M. K. (2005). Social-demographic, school, neighborhood, and parenting influences on academic achievement of Latino young adolescents. Journal of Youth and Adolescenc, 34(2), 163-175.

Epstein, J. L. \& Voorhis, F. V. (2001). More than minutes: Teachers ${ }^{\text {ee }}$ roles in designing homework. Educational Psychologist, 36(3), 181-193.

Ethiopian Third National Learning Assessment of Grade Eight Students (2008) NEAEA, MOE, Addis Ababa.

Ermisch, J.\& Francesconi, M. (2001), The effects of parents' employment on children's lives. London: Family Policy Studies Centre for the Joseph Rowntree Foundation.

Feiman-Nemser, S. (2001). From Preparation to Practice: Designing a Continuum to Strengthen and Sustain Teaching. Teachers College Record, 103, 1013-1055.

Fennema, E., \& Sherman, J. (1976, 1986). Fennema-Sherman mathematics attitudes scales: Instruments designed to measure attitudes toward the learning of mathematics by females and males. JSAS Catalog of Selected Documents in Psychology, 6(31).

Finn, J. D., \& Achilles. C. M. (1999). Tennessee es class-size study: Findings, implications, misconceptions. Educational Evaluation and Policy Analysis, 21(2), 97-109.

Fluty, D. (1997). Single parenting in relation to adolescents' achievement scores. Research Center for Families and Children, 6, 4-8.

HMSO, (2004), 'Science and Innovation Investment Framework 2004-2014', July, ISBN:1-84532-031-X.

Hochschild, J. L. (2003). Social Class in Public Schools. Journal of Social Issues 59(4), 821-840.

Hoyle, E. (1986). Policies of school management. Suffolic: The Press Ltd.

Hull, J. (1990). Socioeconomic status and native education. Canadian Journal of Native Education, 17, 1-14.

Human Resources Development Canada, Statistics Canada, \& Council of Ministers of Education Canada (2001). Measuring up: The performance of Canada's youth in reading, mathematics and science. Ottawa: Authors.

Jeynes, W. H. (2002). Examining the Effects of Parental Absence on the Academic Achievement of Adolescents: The Challenge of Controlling for Family Income. Journal of Family and Economic Issues, 23 (2), 189-210.

Ma, X., \& Klinger, D. A. (2000). Hierarchical linear modelling of student and school effects on academic achievement. Canadian Journal of Education, 25, 41-55. 
Magno, C. (2003). Relationship between attitude towards technical education and academic achievement in mathematics and science of the first and second year high school students Caritas Don Bosco School, SY 2002 - 2003. ED 505 870. Retrieved May 5, 2011, from ERIC databases.

McNeal, R. B. (2001). Differential effects of parental involvement on cognitive and behavioral outcomes by socioeconomic status. Journal os Socio-Economics 30(2), 171.

TGE (1994). Education and Training Policy. Addis Ababa.

Turhan, F., Aydoğdu, M., Şensoy, Ö. \& Yıldırım, H. İ. (2008). Analysis of the relationship among cognitive growth, science achievement, attitudes towards science and gender of the eighth graders Kastamonu Journal of Education, $16(2), 439-450$. 